\title{
COOPERAÇÃO E CONCORRÊNCIA: EVIDÊNCIAS DO COMPORTAMENTO COOPETITIVO NO RELACIONAMENTO ENTRE EMPRESAS AGLOMERADAS
}

Jérsica Florindo ${ }^{1}$

Flávia Oliveira $^{1}$

Rosangela Sarmento Silva ${ }^{1}$

${ }^{1}$ Universidade Federal de Sergipe 


\section{COOPERAÇÃO E CONCORRÊNCIA: EVIDÊNCIAS DO COMPORTAMENTO COOPETITIVO NO RELACIONAMENTO ENTRE EMPRESAS AGLOMERADAS}

Resumo: Um dos desafios que pequenas empresas enfrentam na atualidade é o de manter-se atuantes num mercado cada vez mais competitivo. Nesse cenário, as redes de cooperação se apresentam como uma estratégia precisa na garantia de sua sobrevivência e atuação frente às grandes organizações. O presente estudo objetiva realizar uma análise de rede, com foco nas ações de cooperação e concorrência que evidenciem o comportamento coopetitivo entre atores de empresas aglomeradas do ramo alimentício na cidade de Paulo Afonso-BA. A pesquisa é caracterizada como um estudo de caso, por meio da abordagem qualitativa do tipo descritiva. Os resultados demonstram que o relacionamento colaborativo pouco denso e centrado em poucos atores, bem como os benefícios para a cooperação em rede, fortalecem os argumentos que evidenciam o comportamento coopetitivo no relacionamento entre empresas aglomeradas.

Palavras-chave: Redes de Cooperação. Aglomerado de Pequenas Empresas. Coopetição.

\section{$1 \quad$ Introdução}

As redes de cooperação entre empresas têm se mostrado eficientes meios de garantia de atuação no mercado dos negócios cada vez mais competitivo. Esse cenário de representatividade das redes no âmbito organizacional já é um reflexo de organização social. Oliveira e Lopes (2014) consideram que a perspectiva das redes deve ser considerada como inerente à vida social, especialmente, quando se observa o fato de que não é viável (ou mesmo possível, segundo os autores) para um dado ator - seja ele uma pessoa ou organização - viver de forma completamente independente e isolada de outros e em múltiplas instâncias.

Devido à competição acirrada no meio empresarial, as pequenas e médias empresas apresentam algumas dificuldades para sobreviverem no mercado (LIMA e GEHLEN, 2006). As autoras defendem ser necessário buscar alternativas para um melhor desenvolvimento, crescimento e, sobretudo, a manutenção das pequenas e médias empresas, visto que geram empregos e movimentam o sistema econômico e social.

Por esse motivo, o estudo objetiva realizar uma análise de rede, com foco nas ações de cooperação e concorrência que evidenciem o comportamento coopetitivo entre atores de empresas aglomeradas, através de um estudo de caso de um aglomerado do ramo alimentício na cidade de Paulo Afonso-BA. Segundo Bitante (2019), aglomerados constituem empresas que se reúnem geograficamente e estrategicamente em aglomeração para promover algumas vantagens e impulsionar um desempenho maior, através de uma ação cooperativa.

Para esse fim, estruturou-se o trabalho de forma que primeiramente fosse realizado um levantamento da literatura acerca da teoria entre redes interoganizacionais e conceitos de coopetição. A seguir, são apresentados os procedimentos metodológicos da pesquisa, para finalmente adentrar nas características da rede e na discussão dos resultados apresentados 
pelos dados colhidos quanto aos aspectos e cooperação, concorrência e coopetição entre empresas.

\section{Redes Interorganizacionais e Coopetição}

A rede interorganizacional representa a conexão entre empresas, no partilhar das informações e auxílio mútuo. Castells (2000) define uma rede como um conjunto de nós interconectados. Essa perspectiva da rede enfatiza que "as organizações estão inseridas em um contexto social de relacionamentos que têm um histórico e isso afeta as ações e respostas das organizações envolvidas" (BATH e MILNE, 2008, p.1132).

Os autores Oliveira e Lopes (2014) afirmam que as organizações podem se relacionar de três formas: a) competindo entre si por um recurso escasso e/ou maior fatia de mercado; b) colaborando para a obtenção de benefícios; e, c) numa perspectiva mista onde competidores colaboram entre si em algum aspecto de sua atuação. Os autores acrescentam que as duas primeiras modalidades - competição e colaboração - consideradas dois extremos de relacionamento, foram tratadas por muitas vezes como as únicas formas possíveis de interação em uma rede. No entanto, com o avanço dos estudos na área observou-se a existência de uma terceira modalidade, conforme descrito acima, denominada coopetição.

Para Oliveira e Lopes (2014), os cenários caracterizados pela ação competitiva dos atores eram considerados como de perda e ganho. Dessa forma, para obter certo ganho em um determinado aspecto de sua ação, um ator abriria mão de ganhos potenciais se, em alguma esfera, cooperassem com aqueles com quem competem (OLIVEIRA e LOPES, 2014). Resende et al. (2017) defendem que em mercados competitivos, uma alternativa viável para potencializar a competitividade de organizações rivais é a complementaridade de suas competências por meio da colaboração (DONATO, 2017).

Uma vez que as redes de cooperação proporcionam ambiente favorável à aprendizagem e às inovações, é de se esperar que este tipo de relação aconteça independentemente de relação hierárquica entre os atores envolvidos (OLIVEIRA e LOPES, 2014). Com o desenvolvimento dos estudos no campo de pesquisa da cooperação e competição, o conceito inicial de coopetição foi evoluindo, partindo da simples definição de 'competir e cooperar simultaneamente' para uma visão de rede de valor (CHIM-MIKI e BATISTA-CANINO, 2016). Resende et al. (2017) consideram que a adoção do conceito de coopetição se refere a alguns pontos críticos. Segundo os autores, como sua base é a intensidade da competição e da cooperação, é importante examinar cada um e seus efeitos antes de investigar os efeitos simultâneos.

Sintetizando os aportes teóricos de vários autores e oferecendo um conceito integral para este construto, os autores Chimi-Miki e Batista-Canino (2016) consideram que a coopetição é um comportamento híbrido de cooperação-competitiva que ocorre entre redes, organizações ou dentro de organizações, incluindo as relações entre concorrentes, fornecedores, agências governamentais, população local e clientes, sendo resultado de ações conjuntas para atingir objetivos comuns, apesar de interesses individuais. É válido relatar que como a perspectiva contextual de redes de coopetição considera interações ambientais, ela prevê que conjuntos específicos de relacionamentos e interdependências competitivas e 
cooperativas influenciam as percepções de indivíduos, grupos ou organizações (PATTINSON, NICHOLSON, LINDGREEN, 2017).

\section{$3 \quad$ Procedimentos Metodológicos}

Para alcançar os objetivos preteridos no presente estudo, faz-se necessário estruturar metodologicamente a pesquisa. Inicialmente, a pesquisa pode ser caracterizada como descritiva, pelo interesse na descrição dos laços da rede, sua densidade, centralidade. De forma geral, descrevê-la em sua totalidade, com os mecanismos que estiverem disponíveis através de algumas estratégias desenhadas na figura 01.

Yin (2001) registra que a estrutura descritiva também organiza a análise do estudo de caso. Em suas palavras, "uma abordagem descritiva pode ajudar a identificar as ligações causais apropriadas a serem analisadas" (YIN, 2001, p. 112). Dessa forma, aproveitando a associação do autor, a pesquisa também caracteriza-se como um estudo de caso, uma vez que são analisadas as integrações de um aglomerado alimentício específico na cidade de Paulo Afonso-BA, o Sertão Food Park. A escolha desse aglomerado se justifica por constituir o primeiro espaço na cidade, e o único até o final do campo realizado, que reuniu estrategicamente empresas num mesmo espaço para oferecer serviços de alimentação.

Figura 01 - Delineamento da Pesquisa

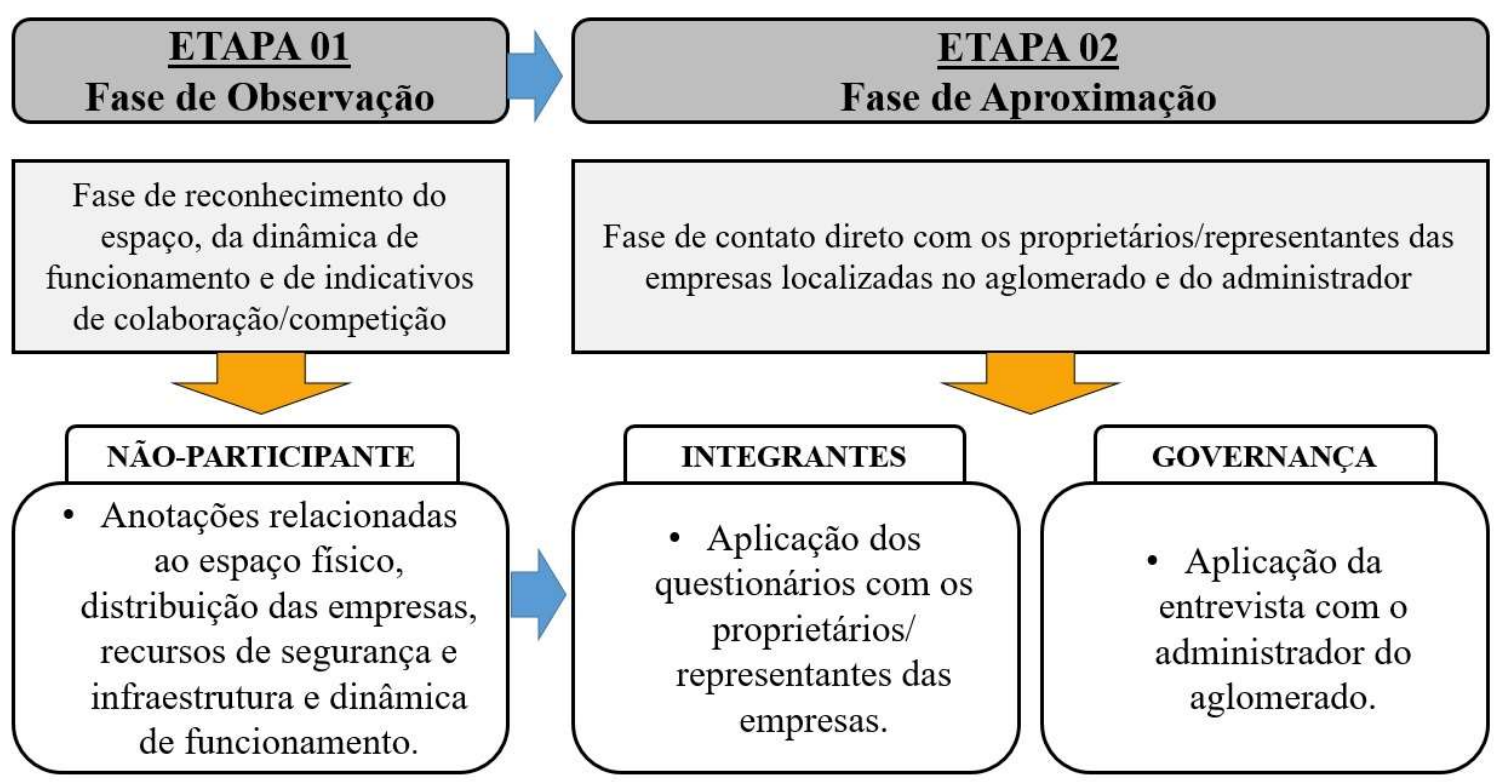

Fonte: Elaborado pelos autores. (2019)

\subsection{Fase de Observação}

Essa fase constituiu a fase inicial da pesquisa, onde foi realizada uma observação não participante, que objetivava fazer o reconhecimento do aglomerado, da dinâmica de seu funcionamento e dos indicativos de colaboração/competição que fossem perceptíveis, quando ainda não ocorreu o envolvimento do pesquisador com as empresas integrantes do aglomerado. Segundo Ferreira et al. (2012), na observação não participante os sujeitos não 
sabem que estão sendo observados, o observador não está diretamente envolvido na situação analisada e não interage com objeto da observação. Essa técnica de observação é reconhecida por Quivy e Campenhoudt (2005) como observação direta, pois o investigador procede diretamente à recolha das informações, sem se dirigir aos sujeitos interessados. Os sujeitos observados não intervêm na produção da informação procurada. (QUIVY e CAMPENHOUDT, 2005; FERREIRA et al., 2012)

Foi nessa fase da pesquisa que ocorreu o reconhecimento das empresas que compunham o aglomerado, permitindo ao pesquisador identificar os principais produtos e serviços ofertados.

Além disso, já foi possível perceber alguns indícios de colaboração conjunta que ficou evidente na atuação dos atendentes de mesa, que, apesar de não serem muitos, não se restringiam a mesas específicas para servir os clientes. Eram funcionários que circulavam por todo o espaço com cardápios variados e não privilegiavam uma empresa específica.

Observou-se ainda as boas condições de infraestrutura do ambiente. Todo espaço comum estava muito bem mantido e em excelentes condições de uso. A Tabela 01 apresenta o registro dos aspectos externos e da área comum do aglomerado, em termos de infraestrutura, atrações e segurança.

\begin{tabular}{|c|l|}
\hline \multicolumn{2}{|c|}{ Tabela 01 - Aspectos Externos e da Área Comum } \\
\hline Infraestrutura & $\begin{array}{l}\text { - As mesas disposta por entre todo espaço eram padronizadas e } \\
\text { numeradas em sua totalidade; } \\
\text { - Na parte lateral há um telão de led que expõe propagandas do } \\
\text { mercado local (clínicas de saúde, academias de ginástica, entre } \\
\text { outros). Observou-se que nenhuma delas fazia alusão à qualquer } \\
\text { empresa do ramo alimentício, que pudesse ser potencial } \\
\text { concorrente das empresas ali instaladas; } \\
\text { - Banheiros bem estruturados e bem mantidos; }\end{array}$ \\
\hline Atrações & $\begin{array}{l}\text { - Na parte central, está disposto um pequeno palco, onde atrações } \\
\text { musicais se apresentavam com música ao vivo; }\end{array}$ \\
\hline Segurança & $\begin{array}{l}\text { - Haviam câmeras de segurança percebidas em cinco pontos do } \\
\text { espaço, bem como um agente de segurança no hall de entrada. }\end{array}$ \\
\hline
\end{tabular}

Fonte: Elaborado pelos autores. (2019)

$\mathrm{Na}$ fase de observação, o pesquisador inferiu que esses registros da área externa e área comum do aglomerado possivelmente eram resultado de uma ação conjunta entre as empresas, uma vez que, pela qualidade e expressividade desses ambientes, era pouco provável que fosse fruto da manutenção de apenas uma empresa. Inferência essa que se confirmou quando a segunda fase da pesquisa foi realizada. 


\subsection{Fase de Aproximação}

A fase de aproximação é a segunda fase da pesquisa onde ocorre o contato direto com os proprietários/representantes das empresas localizadas no aglomerado, bem como com o administrador geral. Essa parte é considerada a fase mais madura da pesquisa, pois ela ocorre num momento em que já se realizou um levantamento da literatura que fundamenta o objetivo do estudo, especialmente sobre a constituição, cooperação e coopetição em rede, bem como já há um entendimento preliminar sobre o funcionamento do espaço, agregado pela Fase 1.

Segundo Fick (2013), há três formas principais de coleta de dados na pesquisa social: fazendo perguntas às pessoas (mediante pesquisas de levantamento e entrevistas), observando-as ou estudando documentos. O presente estudo adotou além da observação, a técnica de levantamento de dados padronizados, através da aplicação de questionário para os proprietários/representantes das empresas aglomeradas no Sertão Food Park, mas também através da realização de uma entrevista com o administrador geral do espaço. O questionário foi adaptado dos estudos de Silva et al. (2014). Para a validação da entrevista, um roteiro preliminar foi enviado para especialista doutora na área de redes e, após aprovado, seguiu para realização.

$\mathrm{Na}$ fase da entrevista, foi possível perceber o papel da governança na rede. Cruz et al. (2007), definem governança como "um processo de coordenação de atores, para alcançar propósitos próprios discutidos e definidos coletivamente, desenvolvendo a orientação e a legitimidade ao conjunto, entre outras coisas, que estabeleçam interação entre atores públicos e privados" (CRUZ et al, 2007, p. 03). Na função de gestor, o responsável pelo espaço cuida da parte administrativa, sendo auxiliado por um conselho que representa os atores da rede, na tomada das decisões estratégicas para funcionamento do negócio. O gestor se apresenta como figura determinante no planejamento das ações da rede. Ações essas mantidas através do pagamento de uma taxa administrativa, que financia as ações compartilhadas, tais como atrações musicais, atividades de marketing, manutenção, entre outros. Em sua ótica, a parte mais difícil na gestão da rede é na área da gestão de pessoas, mais especificamente resolução de conflito de ideias entre os atores.

$\mathrm{Na}$ aplicação dos questionários, os dados foram coletados de forma que o respondente ficou à vontade para fazê-lo, estando o pesquisador próximo para sanar qualquer dúvida que pudesse surgir. Em média, foram necessários entre 30 a 40 min para a finalização de um questionário. $\mathrm{O}$ instrumento objetivava analisar ações de cooperação e troca de informações entre os atores do aglomerado alimentício Sertão Food Park, dividido em 04 (quatro) blocos: Bloco 01 - Informações sobre a rede colaborativa, Bloco 02 - Questões sobre cooperação, Bloco 03 - Questões sobre concorrência e o Bloco 04 - Apresentação do Perfil das Empresas.

Os tópicos a seguir apresentam os dados obtidos em cada um desses blocos.

\subsubsection{Perfil das Empresas}

Os dados foram coletados entre setembro e outubro/2019, a partir de 13 (treze) empresas de pequeno porte na cidade de Paulo Afonso-BA, aglomeradas num espaço partilhado, denominado como Sertão Food Park, que atuam no fornecimento do serviço de alimentação, especialmente fast-foods, mas também refeições mais elaboradas. No entanto, 01 (uma) das empresas se mostrou desfavorável a pesquisa, optando por não responder o 
questionário, o que não constituiu grandes perdas para a dimensionalidade da pesquisa. Observe-se que, ao menos no primeiro bloco do questionário, que observou o relacionamento entre as empresas, sua presença foi registrada uma vez que outras empresas pontuaram colaboração com a referida empresa.

De todo modo, o quarto bloco identificou o perfil das empresas participantes, que segue conforme registrado na tabela 02 .

\begin{tabular}{|c|c|}
\hline \multicolumn{2}{|c|}{ Tabela 02 - Perfil dos participantes da pesquisa } \\
\hline Função & Proprietário- $9 /$ Atendente- $1 /$ Caixa- 2 \\
\hline Gênero & Masculino- 4 / Feminino- 8 \\
\hline Escolaridade & Fundamental- 1 / Médio- 8 / Superior- 3 \\
\hline $\begin{array}{l}\text { Possui outras empresas } \\
\text { fora do aglomerado }\end{array}$ & Sim-3 / Não- 9 \\
\hline $\begin{array}{l}\text { Possui outras empresas } \\
\text { dentro do aglomerado }\end{array}$ & Sim-2 / Não-10 \\
\hline Especialidade & $\begin{array}{l}\text { Empresa } 01 \text { - Comidas nordestinas } \\
\text { Empresa } 02 \text { - Frutos do mar } \\
\text { Empresa } 03 \text { - Parque de Diversão } \\
\text { Empresa } 04 \text { - Sorvete e Café } \\
\text { Empresa } 05 \text { - Coxinhas, Churros, Tapiocas e bebidas } \\
\text { Empresa } 06 \text { - Açaí } \\
\text { Empresa } 07 \text { - Doces, sanduiches e bebidas } \\
\text { Empresa } 08 \text { - Hambúrguer } \\
\text { Empresa } 09 \text { - Petiscos e Bebidas } \\
\text { Empresa } 10 \text { - Pizzas e Massas } \\
\text { Empresa } 11 \text { - Comidas Naturais } \\
\text { Empresa } 12 \text { - não participou } \\
\quad \text { (Observou-se especialidade em pizza) } \\
\text { Empresa } 13 \text { - Hambúrguer, Batata Frita e Milk Shakes }\end{array}$ \\
\hline
\end{tabular}

Destaque-se que $75 \%$ dos questionários aplicados foram respondidos por seus proprietários, $67 \%$ eram mulheres, $92 \%$ com formação de nível médio e superior e $25 \%$ tem empresas fora do aglomerado. Quanto a especialidade, apenas uma empresa oferta serviço de diversão para crianças (Empresa 03), três empresas fornecem culinária especializada (Empresas 01, 02 e 11), duas empresas fornecem gelados (Empresas 04 e 06) e seis empresas fornecem salgados e massas (Empresa 05, 07, 08, 10, 12 e 13).

\subsubsection{Características da Rede}

A apresentação dos dados obtidos nos blocos 01,02 e 03 dos questionários, bem como relatos da contribuição da entrevista, são demonstrados na sessão que segue. Inicialmente, as 
informações coletadas quanto ao relacionamento colaborativo, e indicado pelos respondentes, permitiu a construção do desenho do relacionamento colaborativo na rede, ilustrado na Figura 02 .

Para a realização da análise desses dados, utilizou-se a abordagem de Análise de Redes Sociais (ARS) ou Strategic Network Analysis (SNA). A técnica ARS deu subsídio para utilização do UCINET versão 6.0, um dos aplicativos de software mais conhecidos e usados com mais frequência na realização do SNA, para manusear os dados descritivos e métricas de centralidade e densidade.

Figura 02 - Desenho do relacionamento colaborativo na rede

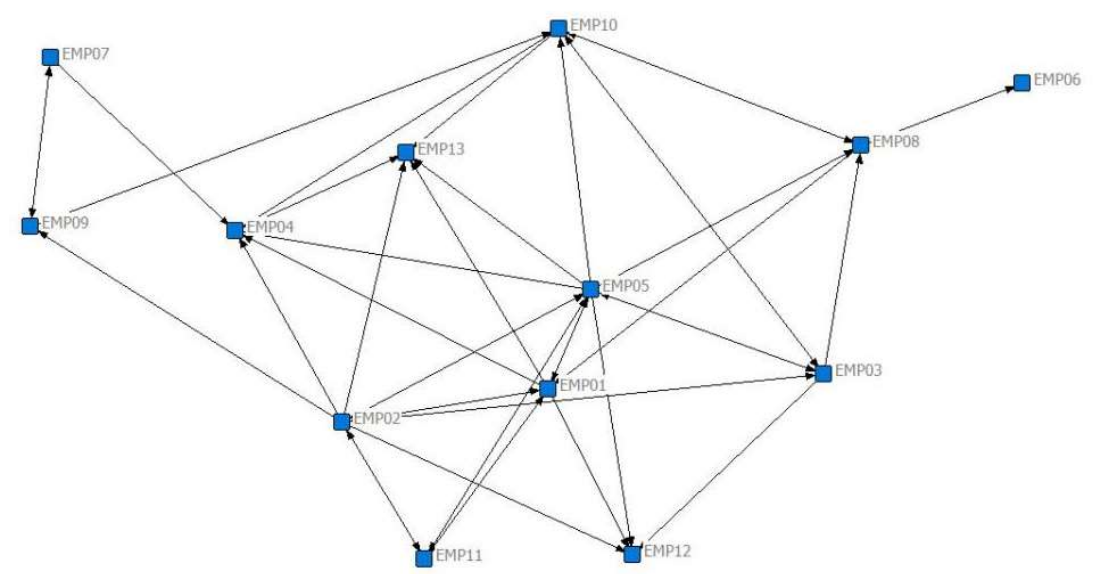

Fonte: Elaborado pelos autores através do software UCINET. (2019)

As redes constituem uma ferramenta importante para representar as interações entre indivíduos ou organizações. Essa interação corresponde às conexões que os atores criam na busca de objetivos comuns (BITANTE, 2019), considerando a intensidade e a frequência com que os atores se relacionam (VERSCHOORE e BALESTRIN, 2008; BITANTE, 2019).

Segundo Bitante (2019), a principal característica dos atores que integram um aglomerado são as suas inter-relações. Dessa maneira, o estabelecimento de vínculos cooperativos entre atores de uma dada rede é essencial para o posicionamento competitivo de cada um desses atores no mercado.

A Figura 02 apresenta um método de medição utilizado na identificação e análise da rede social. Algumas medidas, como a centralidade do grau, são empregadas na descrição das posições das empresas na rede, na identificação das relações interempresas e na determinação de uma rede formada como um todo (BHAT e MILNE, 2008; ERGÜN e USLUEL, 2016).

A rede em análise é reconhecida como uma matriz quadrada e idêntica, por apresentar o mesmo número de filas e colunas em sua representação, sendo a nomenclatura a mesma tanto para as filas quanto para as colunas. Ou seja, segue nomeada de Empresa 01 até Empresa 13, tanto na base da linha como na da coluna. Essa nomenclatura foi adotada como estratégia para manutenção da privacidade das empresas estudadas.

Constitui-se ainda como uma matriz normal, por apresentar fluxos unidirecionais e bidirecionais dentro dela. Essa inferência já evidencia um relacionamento entre atores que não 
necessariamente seja caracterizado por respostas mútuas de compartilhamento. Observe-se, por exemplo, a Empresa 06 que recebe apoio da Empresa 08, mas não corresponde num fluxo bidirecional. Além disso, a Empresa 06 chama atenção por sua posição periférica na rede. Na verdade, se não fosse pelo vínculo com a Empresa 08, seria representada como um nó solto na rede.

A rede em análise pode ser caracterizada ainda como aglomerada (quanto à localização), não-orbital (quanto ao poder de decisão), pequena (quanto ao porte) e formal (quanto à formalização), considerando as contribuições conceituais de Silva (2012).

\begin{tabular}{|l|l|l|l|l|}
\hline \multicolumn{5}{|c|}{ Tabela 03 - Resultados de centralidade para cada ator } \\
\hline Identificador & $\begin{array}{c}\text { Grau de } \\
\text { Saída }\end{array}$ & $\begin{array}{c}\text { Grau de } \\
\text { Entrada }\end{array}$ & $\begin{array}{c}\text { Grau de Saída } \\
\text { Normalizado }\end{array}$ & $\begin{array}{c}\text { Grau de Entrada } \\
\text { Normalizado }\end{array}$ \\
\hline EMP01 & 6.000 & 4.000 & 50.000 & 33.333 \\
\hline EMP02 & 8.000 & 3.000 & 66.667 & 25.000 \\
\hline EMP03 & 4.000 & 3.000 & 33.333 & 25.000 \\
\hline EMP04 & 1.000 & 5.000 & 8.333 & 41.667 \\
\hline EMP05 & 9.000 & 4.000 & 75.000 & 33.333 \\
\hline EMP06 & 0.000 & 1.000 & 0.000 & 8.333 \\
\hline EMP07 & 2.000 & 1.000 & 16.667 & 8.333 \\
\hline EMP08 & 3.000 & 3.000 & 25.000 & 25.000 \\
\hline EMP09 & 2.000 & 2.000 & 16.667 & 16.667 \\
\hline EMP10 & 4.000 & 4.000 & 33.333 & 33.333 \\
\hline EMP11 & 3.000 & 3.000 & 25.000 & 25.000 \\
\hline EMP12 & 0.000 & 4.000 & 0.000 & 33.333 \\
\hline EMP13 & 0.000 & 5.000 & 0.000 & 41.667 \\
\hline
\end{tabular}

Fonte: Dados da rede. (UCINET)

Quanto a centralidade, os resultados da tabela 03 mostram o grau de entrada e saída de todos os nós. As duas últimas colunas são a representação percentual dos referidos graus. Deste modo, pode-se dizer que os atores centrais, em termos de interações recebidas são EMP04 e EMP13, por apresentarem grau de entrada de 5,00 e um grau de entrada normalizado de $41,66 \%$. Quanto às interações concedidas, destacam-se as EMP 05 e EMP02, com graus de 9,00 (33,33\%) e 8,00 (25\%), respectivamente. Assim, as quatro empresas destacadas são percebidas como as que mais apresentam vínculos colaborativos, sugerindo atores mais ativos na rede. A centralidade dá acesso a mais informações, permitindo ações mais rápidas. Geralmente, quanto maior o número de laços de um ator, mais importante e poderoso ele é (CRUZ et al, 2007).

Em termos de densidade, caracteriza-se como baixa (0.269), conforme tabela 3, com um grau médio não tão baixo (3,231), sendo necessário pelo menos três intermediários para que ocorra o contato entre uma organização e outra que não sejam ligadas por elos diretamente. $\mathrm{O}$ desvio padrão de 0,444 sugere uma forte tendência de centralização dos atores, conforme observado na centralidade, sendo mais alto que a densidade média geral da rede. 
Tabela 04 - Densidade da Rede

\begin{tabular}{|l|l|l|l|l|l|}
\hline & Densidade & No. de laços & Desvio padrão & Grau médio & Alpha \\
\hline Indicadores & 0.269 & 42 & 0.444 & 3.231 & 0.827 \\
\hline
\end{tabular}

Fonte: Dados da rede. (UCINET)

A densidade é uma característica da rede como um todo. Segundo Ergün e Usluel (2016), conexões densas são a chave para o desenvolvimento de valores compartilhados e conformidade dentro da rede. Assim, pode-se dizer que uma maior densidade resulta numa comunicação mais eficiente, o que, por sua vez, ajuda a monitorar coletivamente o comportamento das organizações.

\subsubsection{Percepções dos atores quanto aos benefícios da rede}

Muitos são os benefícios encontrados na associação de empresas para a manutenção e desenvolvimento dos negócios. Essas associações impulsionam às empresas associadas a se manterem competitivas (LIU, 2018; CORTESE et al., 2018).

No aglomerado de empresas em análise, através do preenchimento do questionário em respostas aberta, ainda no Bloco 01, os atores foram questionados quanto a percepção dos principais benefícios, considerados aspectos positivos, em se ter uma empresa num espaço compartilhado como acontece no Sertão Food Park. As respostas tabuladas permitiram a construção da Tabela 05 , que além de apresentar a percepção dos atores quanto aos benefícios, estabelece a porcentagem das respostas.

Tabela 05 - Percepção dos atores quanto aos benefícios

\begin{tabular}{|c|c|c|}
\hline Categorias & $\begin{array}{l}\text { Benefícios do } \\
\text { Aglomerado }\end{array}$ & $\%$ de respostas \\
\hline \multirow[t]{2}{*}{ Diversidade } & Diversidade de clientes & $4(19 \%)$ \\
\hline & Variedade nas opções & $2(9,5 \%)$ \\
\hline \multirow{4}{*}{$\begin{array}{l}\text { Divulgação e } \\
\text { Notoriedade }\end{array}$} & Divulgação da marca & $3(14,2 \%)$ \\
\hline & $\begin{array}{l}\text { Espaço em ótimas } \\
\text { condições }\end{array}$ & $2(9,5 \%)$ \\
\hline & Visibilidade & $1(4,8 \%)$ \\
\hline & Localização & $1(4,8 \%)$ \\
\hline Vantagem Financeira & $\begin{array}{c}\text { Aumento da margem } \\
\text { de lucro }\end{array}$ & $2(9,5 \%)$ \\
\hline \multirow{3}{*}{ Suporte cooperativo } & Coletividade & $2(9,5 \%)$ \\
\hline & União & $1(4,8 \%)$ \\
\hline & Igualdade de Valores & $1(4,8 \%)$ \\
\hline \multirow[t]{2}{*}{ Inovatividade } & $\begin{array}{c}\text { Novidade } \\
\text { (aglomerado) }\end{array}$ & $1(4,8 \%)$ \\
\hline & Formato inovador & $1(4,8 \%)$ \\
\hline
\end{tabular}

Fonte: Elaborado pelos autores. (2019)

Após a tabulação dos dados, também foi possível agrupar as respostas em cinco categorias: Diversidade, Divulgação e Notoriedade, Vantagem Financeira, Suporte 
Cooperativo e Inovatividade. Destaque para a possibilidade de diversidade de clientes (19\%) e de divulgação das marcas (14,2\%).

Apesar dos benefícios serem os efetivamente mais destacados, foram apontadas algumas dificuldades/aspectos negativos, tais como: ocasionais desentendimentos $\mathrm{e}$ divergência de opiniões.

\subsubsection{Cooperação e Concorrência em rede}

No contexto da rede de empresas, a cooperação e a troca de conhecimentos entre atores numa dada rede é fundamental para seu fortalecimento. No entanto, mesmo nesses casos, os indícios de concorrência são presentes e frequentes, destacando essa relação. Felzensztein et al. (2018) perceberam correlações positivas e significativas entre cooperação e competição, destacando que economias de escala compartilhada devem aumentar a cooperação entre empresas para reduzir custos e melhorar a competitividade de seus membros.

Nessa discussão emerge o conceito de coopetição. O equilíbrio entre 'concorrência' e 'cooperação' constitui um fenômeno conhecido como coopetição (FELZENSZTEIN et al, 2018; PATTINSON et al, 2018; CORTESE et al., 2018). O conceito parece paradoxal, mas ele surge no momento em que se percebe a coexistência da cooperação e concorrência, seja em nível individual ou empresarial.

Para perceber como o relacionamento cooperativo e competitivo são demonstrados na rede em análise, em resposta ao objetivo central do presente estudo, são apresentadas as questões destacadas nos blocos 02 e 03 do questionário, conforme gráficos 01 e 02 .

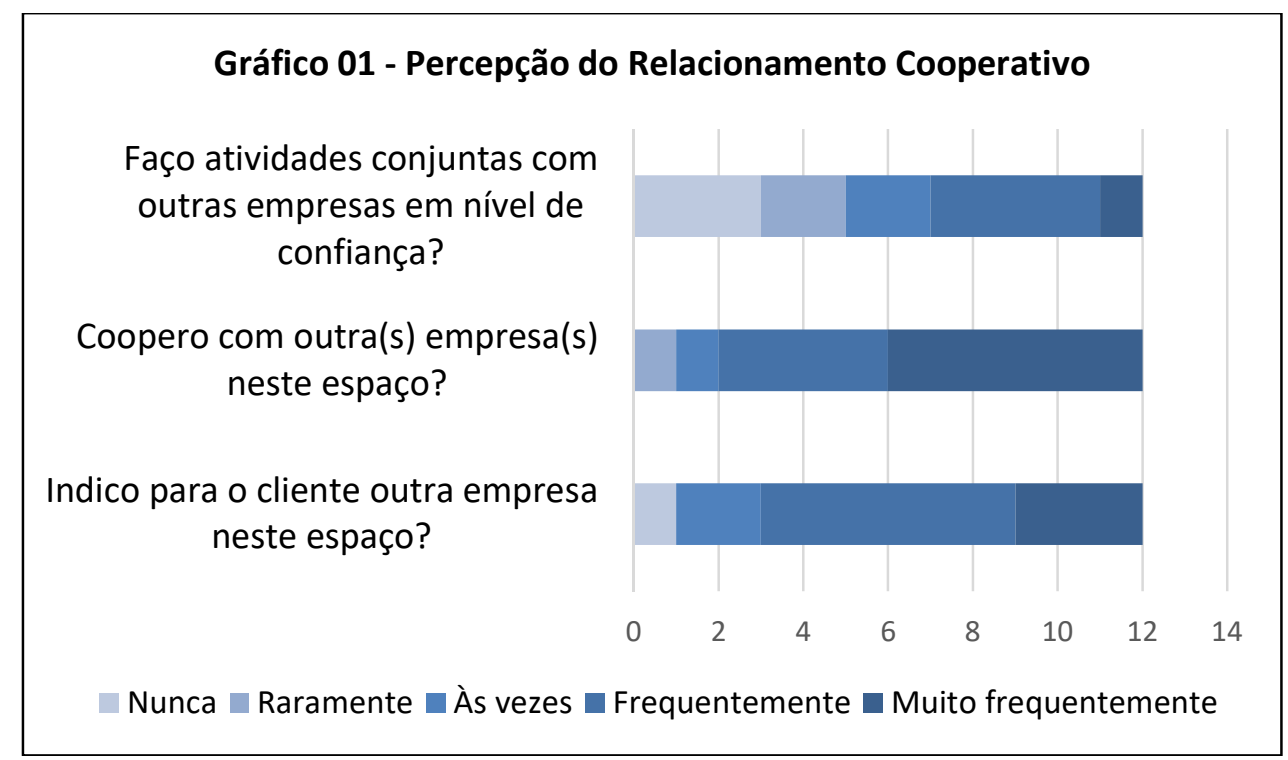

Fonte: Elaborado pelos autores. (2019)

Os atores foram questionados sobre a realização de atividades conjuntas em nível de confiança e cooperação, bem como sobre a existência de concorrência, podendo as respostas objetivas variar entre nunca e muito frequentemente, na proposta de escala likert. 
Observe-se que, quanto à percepção do relacionamento cooperativo, apesar de uma expressiva incidência de respostas positivas para a cooperação frequente e muito frequente, o registro de atores que nunca e raramente fazem atividades conjuntas com base de confiança é da mesma forma considerável. De certa forma, isso demonstra uma tendência pela cooperação que não descarta totalmente certo receio na atividade.

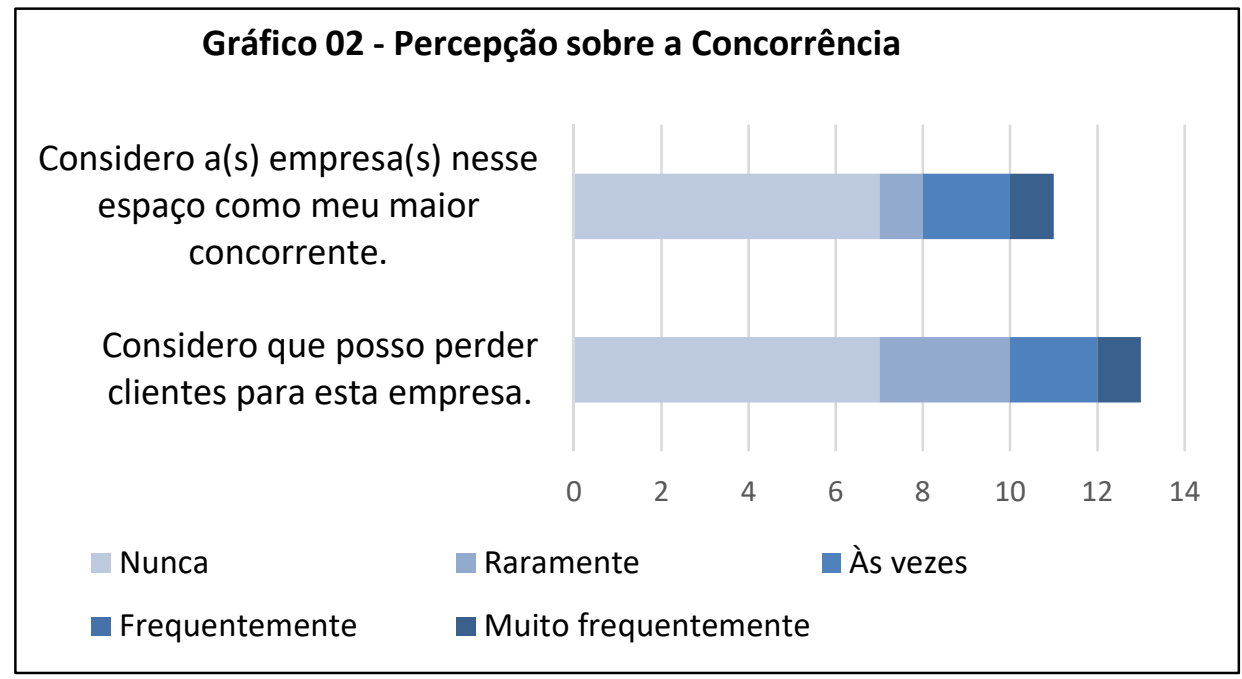

Fonte: Elaborado pelos autores. (2019)

Quanto a percepção sobre a concorrência, os dados revelam um índice baixo de percepção de concorrência, uma vez que há uma boa margem de respostas que não consideram as outras empresas seus concorrentes. Isso, de certa forma, se deve ao fato de que há uma combinação entre os atores para o não comércio de produtos comercializados pelos colegas. Na fala do gestor durante a entrevista, essa percepção fica mais clara "No Food Park, as lojas são praticamente exclusivas, cada uma no seu segmento", que de certa forma é reproduzido pelos atores do aglomerado. Mesmo havendo duas pizzarias, há o entendimento que a proposta de valor é diferente por ser uma de produção com forno à lenha e outra com forno tradicional. $\mathrm{O}$ mesmo acontece com as hamburguerias, sendo uma de produção artesanal e outra tradicional. No entanto, o limite dessa diferenciação de segmento é destacado, tanto pelos atores como pelo gestor, como o principal motivo de discussões e desentendimentos na rede. Felzensztein (2018) destaca que as tensões são inevitáveis num ambiente de coopetição. Isso pode explicar o registro de, mesmo com esse entendimento de segmentação, quase metade dos respondentes que consideram que podem perder clientes para outras empresas ali no espaço optaram decidiram pelo registro de às vezes, frequentemente $\mathrm{e}$ muito frequentemente.

Inferimos assim que, mesmo havendo forte indício de cooperação entre as empresas, não se trata de uma imperiosidade, se fazendo presentes também vestígios da competição, demonstrando, consequentemente, evidências do comportamento coopetitivo no relacionamento entre as empresas aglomeradas no Sertão Food Park. Pattinson (2018) destacou que "a coopetição envolve colaboração simultânea entre duas empresas, de forma 
que ocorra em nível diádico, por exemplo, quando dois concorrentes cooperam dentro de uma aliança estratégica (PATTINSON, 2018, p. 25)

\section{Considerações Finais}

O presente estudo intentou realizar uma análise de rede, com foco nas ações de cooperação e concorrência que evidenciassem o comportamento coopetitivo entre atores de empresas aglomeradas do ramo alimentício na cidade de Paulo Afonso-BA.

Os resultados indicaram que o desenho do relacionamento colaborativo pouco denso e centrado em pouco mais de duas empresas, unido ao registro de benefícios pontuais para a cooperação em rede percebido pelos atores - tais como Diversidade, Divulgação e Notoriedade, Vantagem Financeira, Suporte Cooperativo e Inovatividade -, fortalecem os argumentos do estabelecimento da coopetição na rede analisada.

Este estudo confirma a existência de altos índices de cooperação e índices de concorrência consideráveis, que apontam um comportamento coopetitivo na representação das empresas alocadas naquele espaço. Sendo assim, a contribuição da pesquisa se estabelece na análise de uma rede, encontrada dentro de um contexto cooperativo e competitivo para a associação baseada na estratégia de coopetição.

Algumas sugestões podem ser destacadas para possíveis estudos futuros, como a possibilidade de investigar o papel da governança em redes coopetitivas e verificar a relação da liderança com os atores da rede. $\mathrm{O}$ tema da coopetição em rede abre espaço para o desenvolvimento de novos estudos visando uma melhor compreensão da complexidade que caracteriza as relações interorganizacionais de empresas que coopetem entre si.

\section{$5 \quad$ Referências}

BHAT, S. S., MILNE, S. Network Effects on Cooperation in Destination Website Development. Tourism Management. v. 29, p. 1131-1140. 2008.

BITANTE, A. P. As implicações de liderança no desenvolvimento e manutenção de conglomerações regionais. 2019. 211f. Ensaio (Pós-Doutorado em Administração). Universidade Federal do ABC/UFABC, Abril/2019.

CASTELLS, M. (2000). The rise of the network society (2nd ed.). Malden, MA: Blackwell Publishers.

CHIM-MIKI, A. F; BATISTA-CANINO, R. M. A Pesquisa sobre Coopetição: em direção a uma melhor compreensão do construto e sua aplicação no turismo. Revista Turismo - Visão e Ação - Eletrônica, vol. 18, n. 3, set. - dez. 2016.

CORTESE, D; GIACOSA, E.; CANTINO, V. Knowledge sharing for coopetition in tourist destinations: the difficult path to the network. University of Turin-Italy, Springer: 2018. Disponível em: https://link.springer.com/article/10.1007\%2Fs11846-018-0322-Z 
CRUZ, J. A. W.; ROSA, R. R.; GUINDANI, R. A.; MARTINS, T. S. Governança em Redes: Estudo de caso em uma rede de associação de catadores de materiais recicláveis de rua. XXXI EnAnpad. Set. 2007. Disponível em: http://www.anpad.org.br/admin/pdf/APS-A2046.pdf

DONATO, H. C. Aspectos relacionais da cocriação de valor como uma plataforma de engajamento em rede. 2017. 308f. Dissertação (Programa de Pós-Graduação em Administração). Universidade Municipal de São Caetano do Sul, 2017.

ERGÜN, E., USLUEL, Y. K. An Analysis of Density and Degree-Centrality According to the Social Networking Structure Formed in an Online Learning Environment. Educational Technology \& Society. v. 19, n. 4, p. 34-46, 2016.

FELZENSZTEIN, C.; GIMMON, E.; DEANS, K. R. Coopetition in regional clusters: Keep calm and expect unexpected changes. Industrial Marketing Management. 69, p. 116-124. 2018 .

FERREIRA, L. B., TORRECILHA, N., MACHADO, S. H. S. A Técnica de Observação em Estudos de Administração. XXXVI Encontro da ANPAD. 2012. Disponível em: http://www.anpad.org.br/admin/pdf/2012 EPQ482.pdf

FLICK. U. Introdução à Metodologia da Pesquisa. Parte III: Trabalhando com Dados. p. 105-177. Porto Alegre: Penso, 2013. ISBN 978-85-65848-08-4

LIU, C. H. S. Examining social capital, organizational learning and knowledge transfer in cultural and creative industries of practice. Tour Manag, 64(1), p. 258-270, 2018.

LIMA, M. I. R; GEHLEN, L. Co-opetição em uma rede de cooperação. Revista Gestão e Desenvolvimento, v. 3, n. 2, p. 65-71, 2006.

OLIVEIRA, C. C. G; LOPES, H. E. G. Coopetição em Redes Interpessoais: redes são redes. RAC, Rio de Janeiro, v. 18, n. 4, pp. 508-522, jul./ago. 2014.

PATTINSON, S.; NICHOLSON, J.; LINDGREEN, A. Emergente coopetition from a sensemaking perspective: a multi-level analysis. Industrial Marketing Management. 68, p. 25-35. 2018.

QUIVY, R. CAMPENHOUDT, L. V. Manual de Investigação em Ciências Sociais. 4a ed. Quinta Etapa: A Observação. p. 155-207. Gradiva, 2005.

RESENDE, L. M. M; VOLSKI, I; BETIM, L. M; CARVALHO, G. D. G; BARROS, R; SENGER, F. P. Critical success factors in coopetition: evidence on a business network. Industrial Marketing Management, 68, p. 177-187, 2017. 
SILVA, R. S., ARAÚJO, M. F., FARINA, M. C., SILVEIRA, M. A. P. Ações Conjuntas e Troca de Informações existentes entre Pequenas Lojas de um Shopping Atacadista de Moda. Revista da Micro e Pequena Empresa, Campo Limbo Paulista. v. 8, n. 2, p. 38-53, 2014. ISSN 1982-2537.

SILVA, Rosangêla Sarmento. Relacionamento interorganizacionais em rede de cooperação: um estudo no setor farmacêutico varejista do estado de São Paulo. 2012. 172f. Dissertação (Mestrado em Administração) - Universidade Municipal de São Caetano do Sul, São Caetano do Sul, 2012.

VERSCHOORE, J. R. S.; BALESTRIN, A. Fatores competitivos das empresas em redes de cooperação. In: Enanpad, n. 30, Salvador: ANPAD, 2006.

YIN, R. K. Estudo de caso: planejamento e métodos. 2. ed. Porto Alegre: Bookman, 2001. 